\title{
Facebook and urban kinship in Suva, Fiji
}

\author{
Karen J. Brison
}

\section{(2) OpenEdition}

Journals

\section{Electronic version}

URL: http://journals.openedition.org/jso/7707

DOI: $10.4000 /$ jso. 7707

ISSN: $1760-7256$

\section{Publisher}

Société des océanistes

\section{Printed version}

Date of publication: 15 December 2017

Number of pages: 209-220

ISSN: 0300-953x

\section{Electronic reference}

Karen J. Brison, "Facebook and urban kinship in Suva, Fiji", Journal de la Société des Océanistes [Online], 144-145 | 2017, Online since 15 December 2019, connection on 15 March 2021. URL: http:// journals.openedition.org/jso/7707 ; DOI: https://doi.org/10.4000/jso.7707

\section{(c) (i) (9)}

Journal de la société des océanistes est mis à disposition selon les termes de la Licence Creative Commons Attribution - Pas d'Utilisation Commerciale - Pas de Modification 4.0 International. 


\title{
Facebook and urban kinship in Suva, Fiji
}

by

\author{
Karen J. BRISON ${ }^{*}$
}

\begin{abstract}
Facebook both reflects and reinforces emerging patterns in kinship among urban indigenous Fijians created by challenges to age and gender stratification posed by younger and female relatives with good jobs in town. Changes are also created by an emerging indigenous Fijian middle class who identify with a transnational middle class and have aspirations to migrate overseas in the wake of three decades of political instability. Facebook posts reflect and reinforce movements away from traditional age and gender hierarchies and toward social class stratification. These changes are also found in changing modes of sociality outside of Facebook.
\end{abstract}

KeYwords: Fiji, kinship, Facebook, rural-urban networks

"Hey no facebooking!",

Tutu (Grandfather) Jalesi, the senior member and leader of a lineage from a small village on one of Fiji's southeastern islands, admonished the many descendants of his numerous siblings who lived in Suva and had gathered at his house there to drink kava and plan a trip to attend a reunion of his mother's family.

"Yes, no facebooking,"

echoed Tai (Grandmother) Sera, Tutu's older brother's widow.

\section{RÉSUMÉ}

Facebook reflète et renforce de nouveaux schémas sociaux créés par les défis que les jeunes et les femmes apparentés, dotés d'un bon travail en ville, lancent à la stratification en terme d'âge et de genre qui existe au sein des relations de parenté. Ces changements sont aussi le fait d'une classe moyenne fidjienne en émergence qui sidentifie à la classe moyenne transnationale et souhaite émigrer outre-mer après des décennies d'instabilité politique. Les messages sur facebook refietent et renforcent une distanciation par rapport à la hiérarchie traditionnelle basée sur l'àge et le genre au profit d'une stratification basée sur la classe sociale. Ces changements ont également lieu dans les modes de socialité qui existent en dehors de facebook.

Mots-ClÉs: Fidji, relations de parenté, facebook, réseaux ruraux-urbains

"Whenever we drink kava everyone just sits around looking at their mobiles and facebooking! We are supposed to tell stories when we drink kava, talk to each other, not just sit there facebooking!"

The gathered relatives, most of whom were indeed looking at Facebook on their smartphones, looked around and smiled,

"Right, everyone is facebooking!"

After a brief, half-hearted, attempt at conversation, people began to covertly look at their smartphones again, including the anthropologist who took a picture of the assembled relatives all "face-

* Department of Anthropology, Union College, Schenectady, NY, USA, brisonk@union.edu 
booking," and posted it on Facebook. This caused a virtual conversation much livelier than the previous attempt at face-to-face interaction as my post appeared on the Facebook newsfeed of the many of the relatives who were my Facebook friends.

\section{"Hey caught in the act!" "LOL" "No facebooking!"}

popped up on my screen. My neighbor poked me in the ribs with her elbow and discretely gestured with her eyes toward Tutu Jalesi, whispering,

\section{"Hey take his picture too!"}

Tutu Jalesi was looking down at his smartphone, also apparently caught by the lure of Facebook.

This paper examines kinship among urban indigenous Fijians to argue that Facebook both reflects and reinforces emerging patterns that are created by challenges to age and gender stratification posed by younger and female relatives with good jobs in town and by an emerging indigenous Fijian middle class who identify with a transnational middle class and have aspirations to migrate overseas in the wake of three decades of political instability. In a nutshell, I argue that Facebook has become an important component of indigenous kin relations because it facilitates and enhances the ability to keep in touch with far-flung bilateral networks of relatives who live in Suva and other urban centers, in rural villages, and sometimes "in overseas," to maintain access to jobs, places to stay, and other resources. In Fiji, it is misleading to distinguish between rural and urban kinship since most kin groups include people living in cities as well as in villages. Close to 55 percent of Fijians now live in urban areas and there is continual contact between urban and rural relatives who act as a unit to meet obligations at life cycle events (see also Bonnemaison, 1976; Lindstrom, 2011ab on Vanuatu). ${ }^{1}$ Facebook helps rural and urban relatives to stay in contact.

But Facebook is also popular because it allows a shift away from (or an escape from as in the opening example) the formal, protocol bound, communication associated with kava circles and other events involving relatives of unequal rank toward the kind of informal joking characteristic of interaction between equals preferred by many indigenous Fijians. Many indigenous Fijians living in villages are ambivalent about the respectful comportment required in the presence of higher-ranking people, and between adult married brothers and sisters, and criticize those who insist on this behavior in informal contexts. Tolerance of protocol has decreased since new aspirations give prominence to relatives who have good jobs in towns and overseas and can contribute money and access to valuable opportunities, at the same time decreasing the importance of village elders and those with ritual knowledge. Kinship networks, in short, have become broader and flatter as more people look to relatives for access to resources such as jobs and school in a national and even international arena but try to avoid the age and rank stratified nature of traditional kinship. Facebook, used more by wealthier, younger, and more educated people, both reflects and facilitates this transformation.

However, at the same time as it allows indigenous Fijians to escape from traditional hierarchies, Facebook both reflects and reinforces incipient social class differences within kin groups. I argue that people use Facebook to create "styles" (Nakassis, 2016) of interaction that signal class based identities. Those with jobs in urban areas, or with good prospects of acquiring such jobs, use a distinctive style on Facebook that combines English, texting lingo, and both standard Bauan Fijian and local dialects, to create an urban and cosmopolitan identity, which is at the same time very local. In contrast, a few people with very good and very secure jobs communicate on Facebook primarily with multiethnic networks of friends and workmates, rather than primarily with kin, and generally use only English on Facebook. Finally, those living in villages and dependent on wealthier relatives for occasional employment communicate primarily with family and use local dialect. These incipient social class based styles on Facebook carry over also in to real world interactions where poorer and rural people like to socialize primarily with relatives and prefer to drink kava, because it is both closely linked to village based lifestyles and is relatively cheap. Conversely, wealthier relatives often prefer beer and other alcoholic beverages to kava because alcohol is associated with a different, more cosmopolitan, kind of sociality, less associated with local formality and protocol. Through communicating in English with multiethnic friend circles on Facebook, and drinking alcohol instead of kava, wealthier relatives advertize cosmopolitan sophistication.

I focus on two kin groups, Tutu Jalesi's extended family, who hailed from a small village on the island of Kadavu. I came to know this family as hosts to myself and my American undergraduate students during six terms abroad I directed in Suva between 2005 and 2015. I also examine the extended Manu family, a lineage (mataqali) consisting of the surviving members of a set of six brothers and their descendants with whom I lived in the village of Rakiraki in the northeas-

1. Although there have been some studies of transnational Pacific Islander kin networks and of families living in diaspora (Gershon, 2007, 2012; Morton, 2003; Small, 1997) there is little research on kin networks spanning rural and urban areas within Pacific Island nations. 
tern corner of Viti Levu, Fijis main island, for a over two years in total between 1997 and 2003. The Manu mataqali also interacted regularly with descendants of the three sisters in this sibling set.

Like many people from Fiji's southern and eastern islands, many members of Tutu Jalesi's family had been leaving the island to attend secondary school, primarily in Suva, and then settling in Suva for much of their adult life for at least a couple of generations and many members of the family, also typical of Fijians from the southeastern islands, had fairly good jobs in Suva. Tutu Jalesi's family followed a pattern common on the outer islands in which each nuclear family selected one son, often the oldest or the one who was least promising in school, to stay home to grow

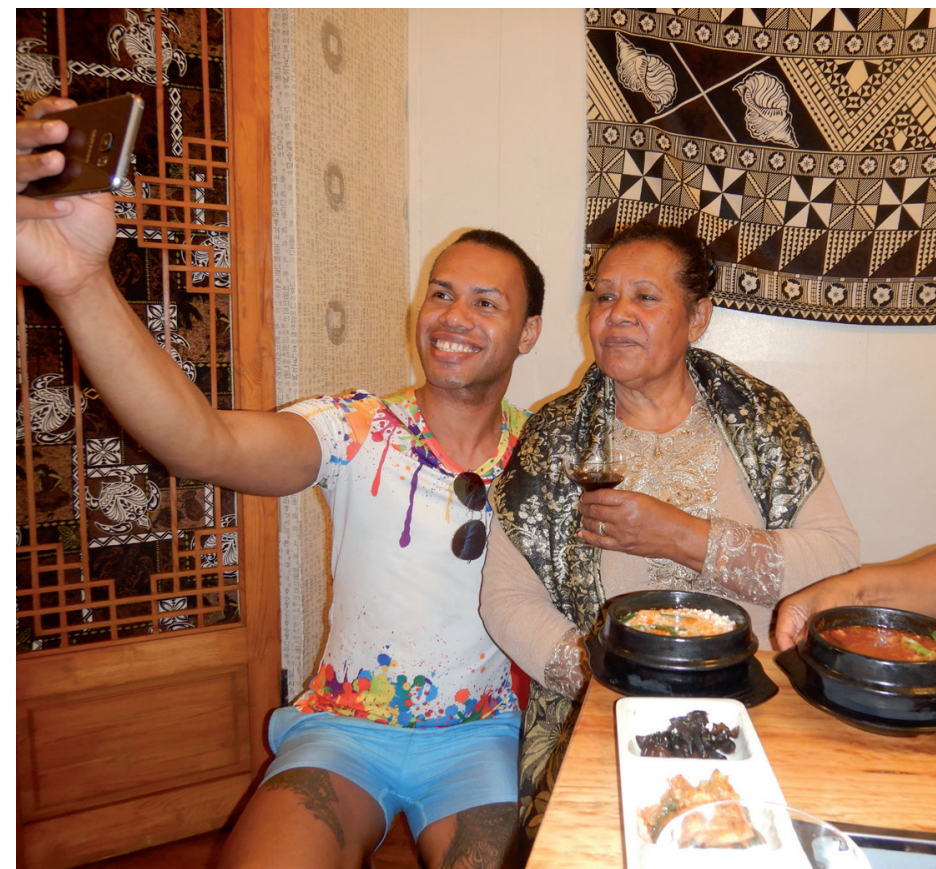

Picture 1. - Every event requires a selfie, Suva, Fiji, 2017 (@ Karen Brison) kava in the village, look after family homes and represent the family in village functions. Many family members had homes in the village where they eventually planned to retire although I didn't know anyone who had done this. In contrast, the Manu clan, as more typical of people from the interior of Viti Levu and from sugar growing areas like Rakira$\mathrm{ki}$, generally stayed in the village for secondary school and had fewer educated family members with good jobs in Suva, although three members of the original sibling set had had careers in Suva or overseas and their children had grown up outside the village.

In Tutu Jalesi's family and the Manu family, there was a continual back and forth between urban and rural areas with urbanites spending school holidays in the village, rural relatives coming to the city on school holidays and each group attending life cycle events in both places. While relatives were dispersed they continued to function as a mataqali for life cycle events and other functions both in Suva and in the village. Furthermore, like most indigenous Fijians, the members of these two families spent part of their lives in rural villages and part of their lives in cities. They saw villages as contexts where more traditional behavior was appropriate and urban areas as zones of relative freedom from traditional protocol where more individual variety in style of comportment and dress was acceptable. So the two groups illustrated somewhat different patterns of rural-urban kinship but both exhibited the typical pattern of continual interaction between rural and urban relatives and individual movement between village and city and the broadening and flattening of kin networks, and emergence of incipient social class

linked styles through Facebook interaction and in other areas of life.

\section{Indigenous Fijian kinship, rural and urban}

Most studies of indigenous Fijian villages focus on rural villages and on the formal, hierarchical, quality of interaction. The neotraditional rural indigenous Fijian community, the vanua, is hierarchically structured with lineages (mataqali) ideally performing specific functions for the group such as priests, warriors, fisherman, and so on although in practice only a few of these lineages are found in many areas of Fiji. Indigenous Fijian communities are patrilineal. The prototypical residential unit is the tokatoka, a sublineage consisting of a set of adult brothers and their descendants although again this structure is not always realized in practice. The hierarchical arrangement of the vanua is echoed in family structure. Christina Toren (1990, 2007), for instance, describes the way relative rank assigned by age, gender, and chiefly status is expressed in use of household space, seating in kava circles, and in seating in church. Toren (2004) further traces the indigenous Fijian sense of self and community to participation in everyday rituals of life that prompt people to see themselves as nodes of relationships based on three key values of veilomani (mutual compassion), veiqaravi (mutual service to each other and to the community) and veidokai (respect). These notions are implicitly hierarchical since veidokai is the respect and 
obedience given by inferiors to superiors who in turn give veilomani, or nurturing love and compassion. However, there is a strong egalitarian element in veiqaravi, the reciprocal service that everyone gives to each other and to the vanua in order to maintain the orderly community that works to bring prosperity to everyone. Katz (1983: 28-29) discusses the emphasis on Itovo vakaturaga (chiefly ways), which involve,

\begin{abstract}
"behav[ing] toward others as if they were person of importance, and knowing their place in the society, they fulfill their traditional obligations to those above them, below them, and at the same level [...] Only through respecting and honoring others, which is to say, through fulfilling one's duties and responsibilities toward others, is harmony possible" (see also Ravuvu, 1987).
\end{abstract}

Respectful behavior is owed toward those of higher rank, toward older generations, toward older siblings, toward opposite sex siblings and toward the spouses of older siblings. When I asked people in Rakiraki what respectful behavior involved, they usually said first that one could not joke with those to whom one owed respect, had to avoid being physically higher than them, had to dress in a long wrap around sulu cloth in their presence, could not talk back when asked to do something, had to avoid their first name even if it occurred as part of a common word, and, in cases where extreme respect was owed, should avoid being in the person's presence altogether. Indigenous Fijian cultures also emphasizes loloma (Katz, 1983: 28), that is loving each other (Brison, 2007), and "sharing and caring" by performing one's role in a community. Becker (1997), for instance, discusses the importance of playing one's role as assigned by age and gender in the community and putting community above self by, for instance, contributing time and resources to communal causes and valuing personal qualities like strength and ability to work that contribute to the community above personal vanity.

Less highlighted in accounts of Fijian kinship are the strong bilateral kin networks, which include sisters' husbands' lineages, mothers' and grandmothers' lineages. For instance, wedding, funerals and life cycle transitions almost always involve delegations and contributions from all of these groups (Ravuvu, 1987). Within the bilateral kindred, relationships with classificatory older siblings and those in older generations require respect while relationships with cross-cousins require a kind of aggressive and sometimes sexual joking. Cross-cousins, for instance, are attacked by audience members when they dance at festivals; the relatives dump baby powder on their heads, stuff candy into their mouths and often make off with pieces of their costumes. In less formal contexts, cross-cousins tease each other about speaking English poorly, being uneducated kai colo (people from the interior; with a meaning somewhat like hillbilly or redneck) and being overweight and or/having manji or kinky hair. These joking relationships have become increasingly important as people focus on networks to get access to jobs and other areas and are less interested in hierarchical relationships.

In village life, hierarchical protocol is appropriate only on formal occasions such as village meetings and life cycle ceremonies. My neighbor in Rakiraki, for instance, annoyed the extended family by insisting that they observe such formalities as avoiding her first name and doing whatever she told them to do even in informal family gatherings. Likewise, although I heard many times that respectful behavior involved things like not shouting but politely walking up to talk to people in soft tones, I noticed that many people enjoyed calling out lewd and teasing remarks, for instance, to relatives traveling through town on buses. In short, while restraint and respect prevail in some contexts, among close and equal people, joking and teasing are preferred.

Urbanization per se does not necessarily lead to changes in indigenous Fijian kinship since people, as evident above, generally remain committed to kin networks and continue to contribute to lineage exchange obligations when they live in town. Indeed, most people are somewhat dependent on ethnic and kin networks to get access to jobs. For instance, my friend Siteri, Tutu's older brother's daughter, had a good job as an accountant that she had gotten at least in part because her father was a supporter of the company founder, who was also from Kadavu. Siteri, herself, employed her classificatory father's sister, $\mathrm{Nai}$, as a housekeeper and frequently employed her father's sister's daughter, Lina, and father's brother's daughter, Nau, when she needed extra help to prepare for big events. Nau also worked for Tutu Jalesi when his wife was ill and Siteri had found Lina a job as a cleaner in her company. In the somewhat less prosperous Manu family, relatives who lived in town often served as hosts to younger family members who wanted to continue their education after secondary school. More prosperous family members also found jobs for young family members and had helped them gain admission to teacher's college and so on.

However, the increased desire of indigenous Fijians to live in town and get jobs there gave prominence to family members like Siteri who had good jobs and decreased the importance of lineage elders who did not have good jobs. Morton (2003) suggests that Tongans in diaspora often seek to escape the more hierarchical, protocol bound, aspects of Tongan life. Children, for instance, seek autonomy from parents and many people avoid those who claim to be chiefly. Some of these patterns were also evident within Fiji. To- 


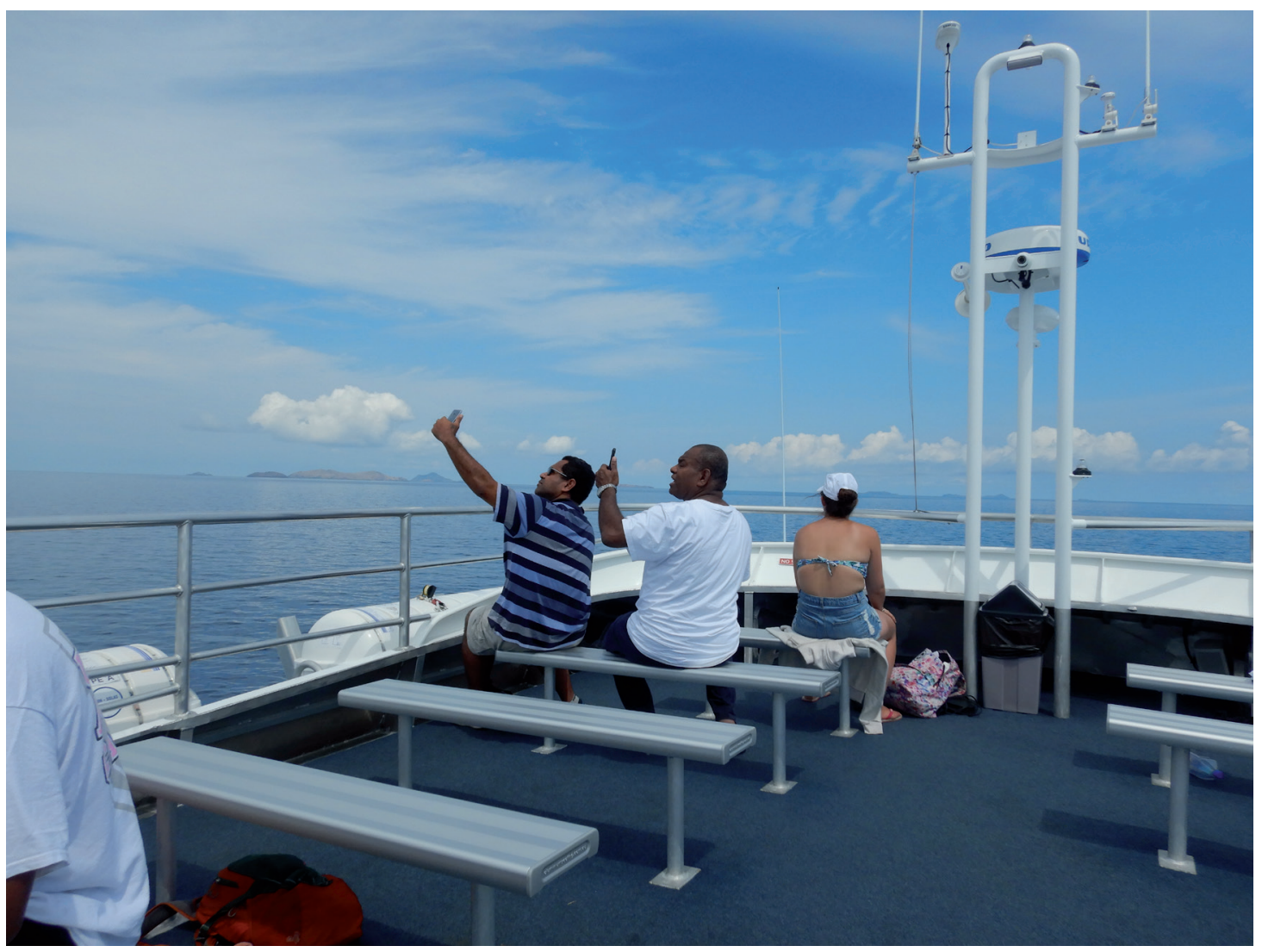

Picture 2. - Capturing a holiday for facebook, outside Port Denerau Fiji, 2017 (C Karen Brison)

ren (2007) found that in 1982 children on Gau island in Fiji were very aware of relative seating position around kava circles and tables according to rank (although their views on gender and rank differed somewhat from their parents) but by 2005 children under eight were less conscious of the ways relatives would arrange themselves spatially. In my observations as well, the increased prominence of family members with good jobs in turn undermined some of the protocol meant to reinforce rank by gender and age since it was not always men or older siblings who had the best jobs. In the Manu family, for instance, one of the younger brothers and one of sisters from the senior generation had very good jobs in Suva. Indeed, since those selected to remain in the village because they were less promising in school became the experts in ritual protocol, these skills and knowledge began to have lesser importance. These patterns were exacerbated by desires to migrate. These conditions all led to broader flatter kin networks. Economic divisions within family groups also, however, produced incipient social class divisions as wealthier relatives, like Siteri, helped poorer relatives but then themselves aspired to escape from kin ties altogether in to a more cosmopolitan world that would perhaps facilitate migration.

\section{Changing Kin Relations on Facebook}

Miller (2011), examining Facebook use on Trinidad, argues that people use social media as a tool to accomplish pre-existing goals such as reinforcing ties with absent relatives, reaching out to people of the opposite sex and so on. Facebook, as a result, does not result in virtual communities but instead enhances existing face-to-face communities. Boyd (2015) similarly argues that American teens use Facebook to conduct a kind of peer centered sociality, away from the eyes of parents, that has long been typical of American teenage lives but has recently been curtailed by increasing parental control. Teens, Boyd argues, lead overscheduled and housebound lives so turn to Facebook to socialize with peers. Boyd further argues that Facebook does not transform social relations; for instance, Facebook socializing seldom crosses traditional ethnic and economic divisions since people "friend" those whom they know in person and carry over distinctive ethnic and class based styles of interaction to Facebook, making it just as difficult for people from different backgrounds to interact in virtual as in actual space. Nevertheless, Boyd (2015) suggests that Facebook, like any media of communication, has "affordances," that is properties that enhance and allow certain kinds of communication while 
making other kinds difficult, and so Facebook inevitably changes relationships in some ways. Gershon (2012) similarly argues that as we use new media of communication we develop shared "media ideologies," that is ideas about appropriate ways to interact on that media, which result in each communicative medium allowing for distinctive kinds of social interactions. ${ }^{2}$

Facebook was a tool that enhanced one kind of socializing among indigenous Fijian kin, that is the informal joking style typical of relations between equals, people of the same gender, and in everyday contexts within extended families. By providing a distinctive medium dominated by young and female relatives, and those aspiring to create identities that were both strongly local and removed from village bound protocol, Facebook facilitated changes in kin relations. Facebook also both reflected and facilitated incipient class based styles within kin networks.

In Fiji, Facebook was a medium that by nature privileged wealthier and younger relatives who could afford smartphones and internet recharge cards and who were comfortable with the technology. Facebook was also a medium generally dominated by women perhaps because they were more likely to be isolated at home looking after children with time on their hands but also possibly because they were often subordinate in families and lineages and so, in general, were more often seeking to escape to a different kind of sociality. For instance, the most active Facebook users at Tutu's kava circles were relatively young women with good jobs in town who were impatient with their subordinate position in traditional ceremonies. A similar distance from village-based sociality among females was revealed when I examined the use of English, standard Bauan Fijian, and the local dialect among children in Rakiraki. I found that little girls spoke more Bauan and English while their brothers often preferred Rakiraki dialect, signaling that girls were more oriented toward lifestyles and identities outside the village than were their brothers (Brison, 2007). Facebook, in short, created a context where younger people, people who lived in urban areas, and women to interact largely without the senior males and brothers whose presence required respect and protocol.

This was particularly evident in the Manu family where only one person older than 45 was on Facebook, and this one person was able to check her Facebook page only about once every six months when she went to town since she was living on her husband's small, fixed, pension so couldn't afford a personal computer or a smart- phone. Those who were employed, their spouses, and their children dominated the Manu family Facebook network. This effectively limited communication to a two-generation group of adults between 35 and 45 and their teenage children. The older generation, who dominated ritual and ceremonial village activity, were not on Facebook and many of the most active Facebook users were female, many of them living away from the village including Buna, a nineteen-year-old attending university in Suva; Mila, a forty-year-old working as a teacher; Ema, a 28-year-old whose husband worked in Suva, and Mata, a woman in her early thirties who lived in Texas. Not coincidentally, all of these women had left the Methodist church, which is closely intertwined traditional village hierarchy and protocol in Fiji, for Pentecostal churches which reject such village based protocol.

Pictures of young mothers and teenaged girls with younger children dominated posts on Facebook. Ema, for instance, posted pictures almost daily of her six-year-old daughter going to school, going to church, and on outings to parks and malls in town. The young university student, Buna, similarly, posted multiple pictures of herself with her roommates and boyfriend on most days, interspersed with religious advice. For instance, one day, she posted eight Christian missives over the course of a few hours including a long message,

\footnotetext{
"When you set your path straight with God, there surely will be obstacles and life's trials that will try to hunt you and crush you! Don't let it distract you! Keep that lamp burning, give Him thanks, don't look back, have faith in your powerful \& magnificent GOD.”
}

Posts tended to highlight Pentecostal church gatherings, school relationships (many of which crossed ethnic lines), and urban activities like eating at the food courts in Suva's malls. Posts also highlighted the nuclear family unit, as well as relationships between husband and wife, girlfriend and boyfriend. Such posts were a distinct departure from traditional village practice where same gender friendships and lineage relationships were emphasized over romantic and marital ties and the nuclear family.

Many of these posts were in impeccable English, indexing both a high level of sophistication and an identity as a sophisticated urbanite (see also Besnier, 2011 on Tongans). This was particularly true of Buna, whose Facebook network greatly expanded when she entered usp. As her posts shifted from pictures of herself and secondary

2 There are few studies of the use of social media among contemporary Pacific Islanders. Morton (2003) comments that young Tongans living in the United States used a online forum to bluntly criticize authority figures and the hierarchical Tongan family structure in ways that would not be possibly in face to face communication. Facebook also allows people to escape from the protocol associated with hierarchical kin relations. 
school mates, to pictures of herself with fellow students at USP, Buna began to post in excellent English.

However, most members of the Manu family posted in broken or text style English interspersed with Fijian words and even a few words of Ra dialect even though many of them were also fluent in English. For instance, Ema, who had been attending usp before she got married, wrote in excellent English but did not often do so on Facebook. One day when she posted a picture of a church gathering, her mother's sister, Mila, joked

"Levu mai na dakhumu. Haha." (Your backside has gotten really big. Haha).

Her classificatory daughter, Ema, responded,

"hahaha 'inaqu [my mother, Ra dialect] am not in any of this pic",

prompting her aunt to comment

$$
\text { "Oi...am sorry...luvequ [my child]." }
$$

This was a typical combination of informal, texting style English exhibited, for instance, in spelling English words like "these" with Fijian phonetic spelling as "this," with a few words of Bauan, the national standard Fijian, exhibited in the aunt's first comment, and a few strategic words of Ra dialect, here the word 'inaqu, the Ra version of tinaqu (my mother). Similarly, before she entered USP when she was still a secondary school student in Rakiraki, Buna posted a picture of herself prompting one of her friends to comment,

\section{"You're a pretty gal... Nd u hav potential."}

\section{Buna responded,}

"Awww vinaka 'avale [thanks cousin, Ra dialect]. Vinaka lewa [thanks darling]. Thanks 4 ca good advice nd support."

This exchange exhibited the same combination of texting lingo, English spelled with Fijian orthography (ca for the), and a few words of Bauan and of Ra dialect.

Besnier (2011) writes that urban Tongans try to escape the traditional rank system by creating new kinds of identities that are both localized and display sophistication in the world outside Tonga. Likewise, Nakassis (2016) suggests that Tamil-speaking university students in southern India, create a distinct "style" of language use that avoids both formal, caste-linked ways of using Tamil and overly correct and fluent use of English. Through avoiding correct, prestigious,
Tamil registers students display their autonomy from local elders and aspirations to a world of good jobs, possibly outside India. But those who speak in fluent and correct English run the risk of appearing to show off and to sell out by denying local cultural identities. Thus the ideal style, involves throwing a few English words in to local sentences.

Fijian Facebook communication exhibited similar tendencies. Facebook users advertised themselves as local through the use of Ra dialect and English words spelled with Fijian orthography, and through the use of typically local jokes such as the comment on the increasing size of the young woman's backside. At the same time, Facebook users showed themselves to be urban and cool through the use of texting conventions, use of English, display of nuclear family and romantic relationships, topics such as commenting on one's "potential," and association with Pentecostal churches. In short, "facebooking" among the Manu reinforced a broad and flat network of adults younger than forty-five and their teenaged children who avoided the protocol bound, hierarchical, nature of Fijian kin relations and created a context where a new kind of cool, young, urban, but still distinctly Ra based identity could flourish.

Facebook use was more widespread and sophisticated in Tutu Jalesi's extended family, since many members of this family had good jobs in the city or overseas. Tutu, himself, for instance, had lived overseas for much of his career serving first with the Fijian Army and then with the UN peacekeeping force. His wife, Tai Alesi, had worked as a teacher in Suva and also abroad. His children, who had both graduated from university in the United States now worked in a local travel agency and with the Fijian government. Tutu's older brother's wife was also a teacher and her children had good jobs in Suva. While Tutu himself was on Facebook along with a classificatory sister from his generation, Facebook in this family network was mostly dominated by adults under 45 and their teenaged children. Again, women were more active on Facebook than their male relatives.

Facebook posts in Tutu Jalesi's family often covered life cycle events like funerals and weddings. But, not surprisingly given the fact that women and children dominated Facebook, posts about life cycle events generally highlighted the parts of these events that women and children participated in such as the preparation and eating of food, decorating the grave and the house and so on. When Tutu's wife, Tai Alesi died, for instance, most of the posts about her came from her daughter, Sereana, and her oldest grandson, Maka, as well as from Nau, who had often been employed as a housekeeper to help Alesi when she was ill. Posts highlighted Alesi as a mother, 
grandmother and friend. For instance, on Mother's Day, a few months after Alesi's death, her daughter posted pictures of herself and her mother along with the message,

"Happy mothers day without a mom isn't exactly a happy one. You're reminded of the safest, warmth, loving feeling that she makes you feel and you can't help but bury your face in the pillow and cry. How do i endure her absence? you don't know pain until God takes a loved one. But with all the happy memories and happy thought she has created now paves my way forward."

There were very few posts highlighting the exchanges of mats, tapa clothes, whales' teeth, and kava that always dominate funerals. Siteri, for instance, posted pictures of a bouquet of flowers sent by myself and the students who had lived with Alesi.

The language of Facebook posts was in some ways similar among Tutu's Jalesi's family and the Manu clan. For instance, when Sereana posted on Mother's Day in English she received replies from various relatives using the same mix of informal, texting English, and informal Fijian as typical of Manu posts,

"Isa really miss her yesterday every mother's day she always cum around home... Isa o nalevu [sigh, senior mother]."

Similarly, when Siteri posted a Happy Birthday message on the page of a close friend, who was from a different area of Kadavu, she wrote in English. But one of her friends, also from Kadavu, commented in a familiar mix of English, texting shorthand, Bauan Fijian and Kadavu dialect,

"Isaaa sa q mai so vei keda... Kaila [sigh, it goes like that with us. Cheers!]. HBD Darling.. Sorry couldnt make it across the globe... Migrane and cold makes me sad... Lol love you always .. Enjoy ur evening... Btw LTC ...weekend at ur house no excuse!!! On On!!”

Here the "on on" referred to Siteri's multiethnic running club, who spurred each other on in their runs with that call.

Facebook styles, however, also revealed incipient social class based identities in Tutu's family, a pattern that did not emerge among the Manu family posters, none of whom were more clearly prosperous that the rest. In Tutu's family, a small group of more prosperous relatives used a style on Facebook that showed an identity more linked to a small cosmopolitan middle class than to local family. For instance, Siteri posted pictures of herself almost daily at local restaurants and bars with workmates and friends. Her brother, Tukuna, a dancer employed with a high profile dance troop, also frequently posted pictures of himself with Siteri's children and with his fellow dancers partying around Suva or in various areas of the world where the dance troop performed. Siteri and Tukuna, two of the more successful family members, were also notable for the extent that their Facebook networks, while still involving many family members, were dominated by friends and workmates. Siteri, for instance, often posted pictures of herself with a group of women who had become friends after working with linked companies. When Siteri posted one of her numerous pictures of herself with her youngest daughter, her post received 112 likes, only 10 of which were from family members. Tukana and Siteri showed their orientation toward a world outside of their family and toward a multiethnic middle class group of professionals by posting largely in English. The other frequent poster in Tutu's extended family was Tutu's daughter, Sereana, who again often posted pictures of herself with her children but also generally posted messages in English.

While these more prosperous family members dominated Facebook, a promotional sale on smartphones in fall of 2014 brought some of the less well-employed family members on to Facebook. Their posts reflected the more localized and family bound identity of less affluent indigenous Fijians. They often, for instance, like the Manu family, included local Kadavu dialect in their posts as well as pictures of their home village, something that was much less frequently the case with Siteri, Tukuna, and Sereana. They also often included posts from funerals, weddings, and other family events. Their posts generally pictured the poster with family members.

Finally, their posts reflected a family bound and village bound humor. In fact, one common genre of humor in this crowd involved mocking imitations of the way more prosperous family members posed for Facebook every time they went out. One day, for instance, Nai, Siteri's classificatory father's sister and housekeeper; Lina, who Siteri frequently employed to help out in large events, and Joana, a visiting relative from the village, posted a series of pictures of themselves on Siteri's front patio under the title

"selfie mada [selfie, if you don't mind]."

These pictures clearly mocked the frequent selfies posted by Siteri. One woman, for instance, took pictures of herself posed next to Siteri's car, which frequently figured in Siteri's posts. The responses to this post were entirely in Kadavu dialect.

Facebook, in short, both reflected particular slices of urban kinship and facilitated these ways of interacting. The absence of the older generation and many of the prominent males involved in village protocol, created a Facebook world do- 


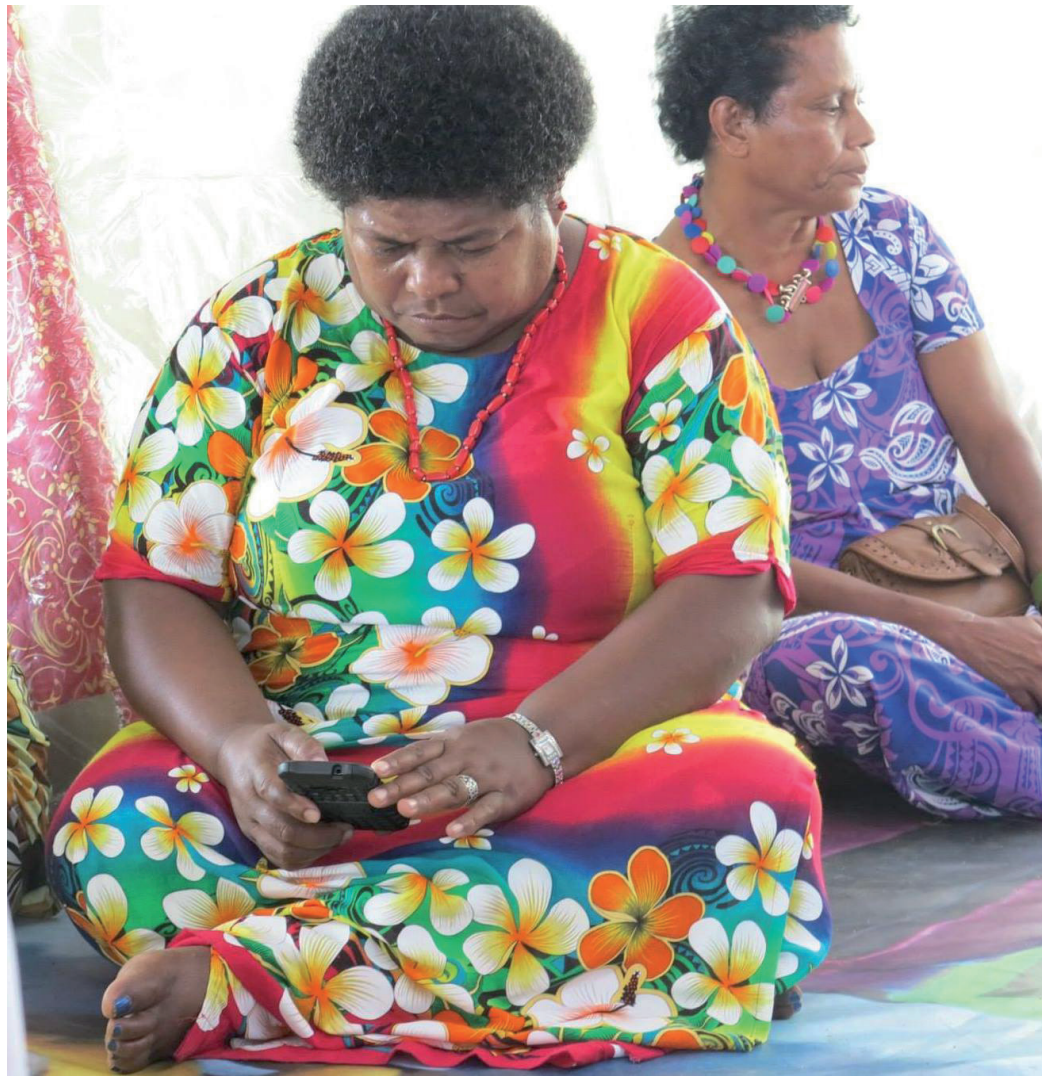

Picture 3. - Facebooking at a wedding, Suva, Fiji, 2017 (@ Karen Brison)

and 2015, and having students stay with Tutu Jalesi, I could see that the patterns on Facebook mirrored those of interaction in real life. Siteri, for instance, frequently hosted and attended events that did not involve her family members. She belonged to multiethnic sports clubs and events associated with these dominated her schedule. She occasionally hosted her extended family for meals associated with life cycle events, like the anniversary of her father's death, her daughter's sixteenth birthday, and for events to raise money and plan for occasions like a trip to a family reunion and another large event to raise funds to relocate their village to higher ground in anticipation of the effects of global warming. More often, however, Siteri had parties that involved a group of women of a si-

minated by women, teenagers, and others who avoided formal protocol. In this world, prosperous family members highlighted their membership in a multiethnic professional middle class by using English and taking pictures of themselves in restaurants, bars, and with friends rather than family. Less prosperous family members, created a kin bound social network but one that reflected the world of women, youth, and lower status people full of joking and teasing and local dialect strategically intermixed with texting style English, that advertized urban sophistication but also in some cases functioned to cover up limitations in ability to write English.

\section{Networking and Authority Outside of Facebook}

The patterns evident in Facebook were also apparent in other areas of family life where there was also a movement away from protocol bound hierarchy toward kin networks stratified by social class. This pattern was most strikingly evident in Tutu Jalesi's largely urban village community.

In the course of staying with Siteri and her nuclear family regularly for stints of two to three months every other year between 2006 milar age to herself whom she had met through the company where she worked.

Siteri's class-based style of sociality was indexed by a preference for alcohol over kava. Siteri would occasionally arrange kava parties for my benefit, because she knew I enjoyed kava, but preferred to drink whiskey, beer, and other alcoholic beverages with her friends. Indeed, when summoned to drink kava with me her friends would often comment that they found kava drinking boring. Alcohol, of course, advertised affluence, since it was more expensive than kava. But it also signaled a more cosmopolitan identity, since European and American tourists drank alcohol but usually disliked kava. When Siteri and her friends drank alcohol, however, they did so in a distinctly local style passing around shots of beer or whiskey that the recipient had to down in one gulp, just as kava was passed around the circle and one had to drain the cup in one drink. Alcohol was also associated with a kind of sociality involving wearing tight, European-style, clothes, going to nightclubs, and breaking free from the polite bounds of normal behavior through expressive "dirty dancing." However, again there was a distinctly local style to this dancing as it generally involved dancing in groups with younger kinsmen brought along for protection and with same-sex friends. Alco- 
hol, in short, signaled a social style that asserted that one was both cosmopolitan and at the same time somewhat local.

A similar association of alcohol with a cosmopolitan style of socializing associated with social class was evident one evening when I arrived at Tutu's house for a meeting to discuss the upcoming reunion of Tutu's mother's family. Tutu was nowhere to be found. Some persistent phoning revealed that Tutu had gone out drinking with some of his old army friends and had forgotten about the meeting. He tried to enlist Nau to hold the meeting for him since she was in any case coordinating the family delegation to this event but was eventually persuaded that she could not hold down the ceremonial place in front of the kava bowl and returned. As he walked in, he grumbled to me across the room that kava drinking was "no good," and that he preferred beer. When you drank beer, he continued, you could express your opinion and there could be a lively and productive debate. Over the kava bowl, however, one had to be tactful and restrained. You had to sit there all night and not say what you really thought and consume so much kava that one emerged groggy the next morning. Here Tutu contrasted an urban alcohol-based style of socializing with workmates with a traditional, village-based style of socializing over kava.

Incipient class divisions with the family were also evident when Siteri hired her less prosperous relatives to do the cooking for her parties and these relatives, generally ate in the back room instead of joining the guests because they disliked the conversation among Siteri's friends who liked to speak English mixed with Bauan, talk about parties they had attended at bars and restaurants, and so on. Over the years, Siteri also made increasing efforts to extract herself from large family gatherings adopting a strategy of sending her children with her mother and her father's classificatory sister, and then making a shorter token appearance herself. In fact, her relatives commented that Siteri would often drop in just long enough to take a picture of herself to post on Facebook, thus establishing her presence, and then would quickly leave telling people that she had been called in to work. Siteri also did not go to the family reunion of her maternal grandmother but instead went to a golf tournament on the other side of Viti Levu while her mother, father's sister and children went to the reunion. Likewise, I only saw Tukana at one of the numerous family events that I attended over the years. As more prosperous relatives like Siteri moved toward a small, cosmopolitan middle class, maintaining village culture became the work of less prosperous relatives. For example, while most of the members of Tutu's village lived in Suva, those who remained in the village were generally in charge of vanua related matters. Siteri's only sibling to remain in the village was regarded as an expert in funeral protocol and in making the speeches that went along with the ceremonial presentations of kava at all life cycle events. In Suva, it was less prosperous relatives who generally did the bulk of the work at life cycle and other events. I spent a great deal of time with Siteri's mother, Tai Sera, who lived with Siteri in Suva for long periods after she retired and was widowed, and her husband's classificatory sister, Nai, who worked as housekeeper and had lived in Suva for most of her adult life. These women, who interacted mostly with family members on Facebook, also spent much of their social life with relatives. I generally attended events at Tutu Jalesi's house with these two women.

Class based divisions, however, remained incipient as rural and urban, prosperous and less prosperous, relatives continued to interact closely and few were so securely prosperous as to risk permanently alienating their kin. When prosperous and less prosperous relatives interacted, there was often a relaxation of protocol creating flatter, less formal kin networks. For instance, Tutu Jalesi was drawn back to the world of protocol, from which he had largely escaped through living much of his life overseas, when the death of Tutu's older brother left the village in Kadavu without a iliuliu (literally: first, leader, a term used for the heads of mataqali). The villagers finally decided to "take back" Tutu’s oldest brother, who had left the village to settle in his wife and mother's village as a young man. In a large ceremony, the oldest brother was brought back to the village and given a fine house built especially for him. But he died just a week later leaving the group without a iliuliu once more. The only remaining members of the generation were Tutu who lived in Suva and had left the village for good as a young man and a cousin who was a schoolteacher in Suva. After much discussion, the role of village leader was given to Tutu who declared that he would move to the village but then said he couldn't do that after his wife developed health problems and had to stay in Suva to be near better doctors.

In Suva, Tutu built a new house with an appropriate room for receiving guests to drink kava, one of the major roles of a village head. The family also supplied him with a rotating crew of young men from the village to help him serve kava to guests since his own son, who lived downstairs, had two jobs to support his large family and, as a Pentecostal Christian, could not drink kava. Tutu received regular visits from the turaga ni koro (literally chief of the village, generally an elected, administrative position) from the village, an appointed official charged with keeping peace in the village and maintaining village buildings and roads. 
Tutu's installation as village headman caused grumbling among some relatives perhaps because the nature of the role began to change as he performed it. Tutu was acknowledged to be rather inadequate as a ceremonial expert. Fijian chiefs usually have younger, lower status, mata ni vanua (literally: the face of the vanua, or herald) to give speeches for them and Tutu also followed this practice by recruiting Siteri's brother from the village to come over when ceremonial work needed to be done such as presenting kava and whale's teeth at family events such as funerals. Tutu, however, often just sent a younger man from the village in his place.

Tutu's behavior caused some gossip among the more village oriented family members such as his brother's widow, Tai Sera and Nai. But Tai Sera also admitted that Tutu, although she found him to be inappropriately interested in his army friends who were now powerful figures in the government dominated by their former commander, Bainimarama, was able to do a lot for family members because of his connections. His son had a government job. He could get resources for the village when he attended provincial government meetings because he had friends in high places. Indeed, even Tai Sera was warm in her praise for the way he had paid school fees and provided housing for many of the young people in the village, including her own children, when they went to secondary school in Suva. One evening, for instance, Tai Sera, a staunch Methodist, got in to a lively debate with Tutu, a self-proclaimed atheist, about the role of religion over the kava bowl. Tutu said that Christianity was just a way of brainwashing Fijians since it had been introduced by the British and was not part of indigenous Fijian culture. Tai Sera argued that Christianity was a universal religion, not tied to any culture, and that it reinforced good and moral behavior. Tutu replied that he was generous with his relatives, as a good Christian should be, even though he never went to church and didn't believe in God. Tai Sera acknowledged that Tutu was a generous man who had been very good to his relatives. Tutu, in short, without realizing it, was participating in a shift in ideas about leaders emphasizing the importance of generosity, made possible by money, and access to resources like jobs and government funds over religious decorum and command of protocol.

The ways that kinship in Tutu's extended family was becoming wider and flatter, was also evident at the reunion of Tutu's mother's family. This event brought together the surviving siblings and descendants of an eleven-member siblings set, the oldest of whom was Tutu Jalesi's mother. Buses were chartered to bring people from Suva to the village from which the family hailed as the majority of those involved lived in Suva or overseas. When we arrived, we presented the traditional sevusevu, a ceremonial presentation of kava, to one of Tutu's mother's brother's children who had retired to the village. But the subsequent festivities on other days involved little of the traditional indigenous Fijian protocol. The descendants of each of the siblings were allocated an area in the community hall; each had chosen a particular color or outfit for their "team" and many, like the Kadavu group, wore "team T-shirts" with the names and pictures of their grandparent. Each was designated a time to present which involved explaining their own family tree often with visual aids and performing a few dances.

The non-traditional nature of the event was encapsulated in the afternoon cocktail party, that preceded the evening's festivities. Afterwards, the relatives congregated in the community hall to drink kava and dance, an event that involved dancing to popular Fijian tunes with cross-cousins jokingly pulling each other up to dance. The next day the Kadavu crowd said that there had been inappropriate "dirty dancing," suitable for nightclubs but not for village events. They explained to me that the women had been very expressive and sexual in their dance moves, probably because they were from Suva and didn't know about village life and because they had gotten drunk at the cocktail party beforehand. In the village one should taralala, that is do a shuffling kind of dance involving walking back and forth in pairs.

\section{Conclusion}

In Fiji, it made little sense to talk about the nature of urban kinship since kin networks stretched between village and city and most individuals spent part of their time in the city and part in rural villages. Rural and urban kin saw each other frequently and participated in common family life cycle and other functions. Facebook provided a means of interaction that both reflected and reinforced changing patterns of kinship that had more to do with an increased desire to get jobs in the city and to migrate overseas than with urbanization per se. As younger and female relatives like Siteri gained increased prominence through good jobs in Suva, and as people focused on kin networks for support outside the village, kin networks became broad and flat and many people sought to avoid the hierarchy bound protocol typical the neotraditional Fijian vanua. Facebook allowed younger people and women to express a new kind of identity that was distinctly local yet expressed a sophisticated urban coolness through use of texting lingo, English and frequent pictures of nuclear families riding in cars, going on vacations in resorts, going to Pentecostal churches and so on. At the same time, Facebook both reflected and 
reinforced social class based divisions within family networks. These changes reflected also real changes outside of Facebook.

\section{REFERENCES}

Becker Anne, 1995. Body, Self and Society: The View from Fiji, Philadelphia, University of Pennsylvania Press.

Besnier Niko, 2011. On the Edge of the Global: Modern Anxieties in a Pacific Island Nation, Palo Alto, Stanford University Press.

Boyd Danah, 2015. It's Complicated: The Social Life of Networked Teens, New Haven, Yale University Press.

Bonnemaison Joël, 1976. Circular Migration and Uncontrolled Migration in the New Hebrides, South Pacific Bulletin 26 (4), pp. 7-12.

Brison Karen J, 2007. Our Wealth is Loving Each Other, Lanham: Lexington Books.

Gershon Ilana, 2007. Converting Meanings and the Meanings of Conversion in Samoan Moral Economies, in Matthew Engelke and Matt Tomlinson (eds), The Limits of Meaning: Case Studies in the Anthropology of Christianity, New York, Berghahn Book, pp. 147-164.

-, 2012a. The Breakup 2.0: Disconnecting over New Media, Ithaca and London, Cornell University Press.

-, 2012b. No Family is an Island: Cultural Expertise Among Samoans in Diaspora, Ithaca and London, Cornell University Press.
Katz Richard, 1983. The Straight Path of the Spirit: Ancestral Wisdom and Healing in Fiji, Rochester Vermont, Park St. Press.

Lindstrom Lamont, 2011a. Urbane Tannese: Local Perspectives on Settlement Life in Port Village, Journal de la Société des Océanistes 133 (2), pp. 255-266 (https://jso.revues.org/6461).

-, 2011b. Vanuatu Migrant Lives in Village and Town, Ethnology 50 (1), pp. 1-15.

Miller Daniel, 2011. Tales From Facebook. New York, Polity Press.

Morton Helen, 2003. Tongans Overseas: Between Two Shores, Honolulu, University of Hawai'i Press.

Nakasis Constantine V., 2016. Doing Style: Youth and Mass Mediation in South India, Chicago and London, University of Chicago Press.

Ravuvu Aselele, 1987. Vaka I Taukei: The Fijian Way of Life, Suva, UsP Press.

Small Cathy A., 1997. Voyages: From Tongan Villages to American Suburbs, Ithaca and London, Cornell University Press.

Toren Christina, 1990. Making Sense of Hierarchy: Cognition as Social Process in Fiji, London, LSE monographs.

-, 2004. Becoming a Christian in Fiji: An Ethnographic Study of Ontogeny, The Journal of the Royal Anthropological Institute 10 (1), pp. 222-240.

—, 2007. Sunday Lunch in Fiji: Continuity and Transformation in Ideas of the Household, American Anthropologist 109 (2), pp. 285-295. 